discharge of some kind was to be provided for. But it is now long since I first brought this matter before the profession, and from the first I have stated that a serous oozing always occurs, profuse and tinged with blood in the first instance, and afterwards diminishing, but almost invariably continuing in small amount for a protracted period. Mr. Spence's charge would have had exactly the same basis as it has, if every case of psoas abscess were cured within a week under antiseptic treatment, provided that during that week, or even during two hours, a serous discharge occurred. My statement had reference to the great new pathological truth of the cessation of suppuration from the pyogenic membrane and carious bone when a vertebral abscess is opened and treated antiseptically in combination with free drainage, while rest is given to the weak part of the spine by the recumbent posture. Under these circumstances, the chronically inflamed osseous tissue has opportunity afforded it to recruit. How long this process of repair may require for its completion varies greatly in different instances, and here and there we meet with a case in which, in consequence of the presence of pieces of dead bone too large to make their way to the surface, complete cure appears impossible. Happily, however, as experience has now amply proved, the great majority of these formerly hopeless cases, highly interesting to the poor creatures affected and to their relatives, though "not" yet "very interesting" to Mr. Spence, admit of complete cure, if patiently treated to the end with strict antiseptic care and rest.

And here again I have to thank Mr. Spence for having, by his reference to my cases left in the Infirmary, brought out incidentally the fact -I had almost said the glorious fact-recorded by Dr. Bishop in the number of the JOURNAL for the 3Ist ult., that under his good care almost all these types of hopelessness, as they might naturally be supposed to have been from the way in which they are alluded to by Mr. Spence, have been restored to health and usefulness.

\section{EXTROPHY OF THE BLADDER.}

By JOHN WOOD, F.R.C.S., F.R.S., Surgeon to King's College Hospital.

THE proverbial troubles of inventors and improvers, like those of parentage, are by no means confined to the throes which attend the birth and delivery. The result must be protected and looked after, sometimes for an indefinite period, and even when it might reasonably be thought to be strong enough to assert its own rights.

The occasion on which I venture to inflict upon the readers of the JOURNAL this somewhat trite moral is in reference to a paper published in the Journal of February 7 th by Mr. J. Greig Smith, of the Bristol Royal Infirmary, on "Two Cases of Successful Operation for Extrophy of the Bladder by a New Method". This paper has afforded me the satisfaction of finding that my former efforts to relieve this deplorable deformity have not been without the result of directing others in what I believe to be the right way of relieving it. In his remarks upon these two interesting cases, Mr. Smith apologetically states that "he has made free use of several methods of operating, rather than invented an entirely new plan". Almost all improvements in the art of surgery have been arrived at by the slow process of building upon the work of our predecessors. But I have looked carefully and in vain through Mr. Smith's paper for any important departure from methods of operating which I have frequently practised, and which have already become public property. It must have been due to an unfortunate chance that my name is mentioned in the paper, in connection with a misapprehension of an inconsiderable part of my method of operating. I have never in any of my now numerous cases employed hare-lip pins, as he states, so as to include "both thicknesses of the transplanted tissue, involving as it does a doubly acute flexure, and consequently a greater or less extensive strain on the tissues", which, he adds, "cannot be otherwise than detrimental". I have, indeed, used hare-lip pins to secure the opposed edges of the groin-flaps over the reversed abdominal flap; and I have frequently made them to take up in the middle line a small portion of the connective tissue on the raw surface of the subjacent reversed flap. But I have never applied them so as to penetrate the whole thickness of the reversed flap, and never so as to produce a doubly acute flexure. They were put in (as all the steps of the operation were conducted) with every whit of the scrupulous gentleness and care so fully emphasised in Mr. Smith's paper, and no more produced the doubly acute flexure which he deprecates than they do in the operation for hare-lip, properly performed. In my late operations, I have found out (like Mr. Smith in other matters) better modes of keeping the flaps together, and for some years have used silver-wire sutures only for this purpose, applied so that they can be easily drawn when the proper time comes.

The strain upon the sutures in this operation depends almost solely upon the forcible protrusion of the hinder wall of the bladder by the action of the expiratory muscles, more than upon the way in which the sutures are made; and no operation which does not take this condition into account will succeed. Sloughing of any portion of the groin-flaps has scarcely ever occurred in my cases; but sloughing has taken place at the lower border of the reversed abdominal flap, just where I understand Mr. Smith to place his elongated portion intended to cover the urethra. Such an elongation of the flap, so far from its vascular connections with the abdomen, and subjected to the pressure of the resilient dartos and the tension of the scrotal skin brought over it, I have found to result frequently in sloughing or atrophy. Still I agree with him in thinking that it is always worth trying for. The plan of extending the groin-flaps downwards as far as the scrotum and side of the penis I have also frequently followed; and I have often found (as $\mathrm{Mr}$. Smith will also find, if he watch his-cases long enough) that, as the upward contraction of the cicatrix progresses and the child grows, the opening left at the root of the penis will enlarge, and in many cases will require some further procedure at a future period. In such an emergency, Mr. Smith will regret the loss of the prepuce by the sloughing he mentions, which seemsto be an instance of the consequences of attempting too much at once. The retention of the urine for half an hour at a time in one of the cases is a very encouraging sign; and it tends to justify the doctrine that I have laid down, that the involuntary tonic contraction of the dartos-fibres connected with the artificial orifice into the bladder goes for something in its production. In several of my own cases, and conspicuously in one which is now under my observation at King's College Hospital, the partial power of retention, much doubted by some surgeons, is also very remarkable.

The plastic method of dealing with this deformity is shown by the cases (now numerous enough) to have been successful in restoring comfort to the patient, keeping him, with the aid of an ordinary railway India-rubber urinal, quite dry, protecting him from the constant irritation of wet clothing, and making him less an object of disgust. It is a far more safe and really a more reasonable method than any of the desperate and theoretical experiments for attaining this end, such as attempts at making a permanent communication between the bladder and rectum, or placing the ureters within the latter cavity by formidable operations, which have invariably produced the most disastrous consequences to the unfortunate patient.

In conclusion, I may add, with reference to Mr. Smith's very successful and interesting cases, that the boracic lotion, with which he carefully washes the surface of the flaps, is a very good and useful application, but that it is not absolutely essential to produce primary union of the flaps in plastic cases.

\section{RECOVERY OF A BROKEN BOUGIE FROM THE BLADDER.}

By GEORGE E. WALKER, L.R.C.P., Medical Officer of Parkhurst Prison, Isle of Wight.

ON the evening of October 6 th, I was sent for to attend G. P., aged 47 , who, I was informed, had broken the bougie-a No. 7-which he was himself in the habit of passing into his urethra for an old stricture. $\mathrm{He}$ informed me that the instrument was an old one that he had had in use for ten months; and that it was cracked across in several places. $\mathrm{He}$ also told me that he had succeeded in passing it quite easily into the bladder, and that the accident happened in withdrawing it. The portion which he produced was seven inches in length, which would leave about five inches as the length of the portion retained. As he appeared to be in great pain, with a highly distended bladder, I found it necessary to give him relief at once. I could feel the broken end nowhere along the track of the urethra, and a No. 7 gum-elastic catheter passed freely down to the stricture, which was situated a few inches above the neck of the bladder, where its further progress was arrested by some obstruction. I was equally unsuccessful with a No. 5 . I then determined to try to push the broken end into the bladder with a silver catheter, as it was evident that the obstructing fragment was situated too far down to admit of its being seized by any urethral forceps. I used a No. 7 for this purpose, and succeeded, without much difficulty, in passing it into the bladder, drawing off about two pints of urine, which afforded him instantaneous relief. In withdrawing the instrument, there was some little difficulty - a circumstance which I attributec to the spasm, and which I shall have occasion to mention hereafter. 